\title{
CUTANEOUS RESPIRATION IN MAN
}

\section{ViI. The Effect of Venous Congestion on the Rate of Carbon Dioxide Elimination and Oxygen Absorption ${ }^{1}$}

By A. CARLTON ERNSTENE AND MARIE C. VOLK

(From the Medical Research Laboratories, Beth Israel Hospital, and the Department of Medicine, Harvard Medical School, Boston)

(Received for publication October 19, 1931)

This communication presents the results of an investigation of the effect of venous congestion on the rate of cutaneous respiration in man.

\section{METHODS AND RESULTS}

The apparatus employed was that designed by Shaw and his associates $(1,2)$. The technical procedure was essentially the same as that followed in studying the effect of drugs on the rate of cutaneous respiratory exchange (3). Measurements were made of the total amounts of carbon dioxide eliminated and oxygen absorbed through the skin of the arm in two successive two-hour experiments. In both periods, the arm was introduced into the plethysmograph to the same extent. The first experiment, in each instance, was a control observation. The subject's arm was removed from the plethysmograph between the two periods, and the apparatus was washed out with room air. The arm was then reinserted, and a pneumatic cuff, $13 \mathrm{~cm}$. wide, was applied. After the first gas sample of the second experiment had been collected, the cuff was inflated to a pressure of 40 to $80 \mathrm{~mm}$. of mercury, and this pressure was maintained throughout the remainder of the period of observation.

The prolonged application of pressure produced extensive edema of the arm. It therefore was necessary to measure the surface area and volume of the part within the plethysmograph after both experiments and correct the results of the experiments for the variations observed in these measurements. Paresthesia and loss of the sensations of touch and position developed gradually in the hand and wrist during the time the pressure was applied. In addition, there was dull aching pain in the arm which became severe toward the end of the observation period. On removing the arm from the plethysmograph, transient paresis of the muscles of the hand and forearm usually was observed and, in the experiments with the highest pressures, numerous petechiae were present.

1 This investigation was aided by a grant from the DeLamar Mobile Research Fund of Harvard University. 
Six measurements of the effect of venous congestion on the rate of cutaneous respiration were made in three normal subjects. All observations were made under controlled conditions of temperature and humidity, and the results of each experiment were corrected to the value they would have had if the temperature within the plethysmograph had been $27^{\circ} \mathrm{C}$. (4). The results of the study are presented in the table.

TABLE I

The effect of venous congestion on the rate of cutaneous respiration *

\begin{tabular}{|c|c|c|c|c|c|c|c|}
\hline \multirow[b]{2}{*}{ Subject } & \multirow{2}{*}{$\begin{array}{l}\text { Pressure } \\
\text { applied }\end{array}$} & \multicolumn{3}{|c|}{$\mathrm{CO}_{2}$ excreted } & \multicolumn{3}{|c|}{$\mathrm{O}_{2}$ absorbed } \\
\hline & & $\begin{array}{c}\text { Control } \\
\text { period }\end{array}$ & $\begin{array}{c}\text { During } \\
\text { venous } \\
\text { congestion }\end{array}$ & Difference & $\begin{array}{l}\text { Control } \\
\text { period }\end{array}$ & $\begin{array}{c}\text { During } \\
\text { venous } \\
\text { congestion }\end{array}$ & Difference \\
\hline & $m m . H g$ & $c c$. & $c c$. & $c c$. & $c c$. & $c c$. & $c c$. \\
\hline 6. & 60 & 155 & 157 & +2 & 83 & 86 & +3 \\
\hline $6 \ldots$ & 40 & 142 & 133 & -9 & 96 & 120 & +24 \\
\hline & 50 & 114 & 157 & +43 & 82 & 94 & +12 \\
\hline & 50 & 135 & 123 & -12 & 80 & 86 & +6 \\
\hline 23. & 80 & 124 & 113 & -12 & 84 & 90 & +6 \\
\hline 23. & 60 & 128 & 140 & +12 & 90 & 95 & +5 \\
\hline
\end{tabular}

* Calculated in cubic centimeters per hour per square meter of skin surface at $27^{\circ} \mathrm{C}$.

\section{DISCUSSION}

With the method utilized, changes in the rate of oxygen absorption through the skin of less than $30 \mathrm{cc}$. per hour per square meter of skin surface and in the rate of carbon dioxide elimination of less than $20 \mathrm{cc}$. per hour per square meter of skin surface cannot be considered significant (3). The maximum change in the rate of oxygen absorption observed in the present investigation was $24 \mathrm{cc}$. per hour per square meter of skin surface, and in only one instance was the rate of carbon dioxide elimination altered by more than $20 \mathrm{cc}$. per hour per square meter of skin surface. It is concluded, therefore, that venous congestion of the degrees employed does not significantly affect the rate of cutaneous respiration.

The metabolic requirements of the skin are supplied in part by the blood and in part by the exchange of carbon dioxide and oxygen between the air and the tissues. Since it may be assumed that the metabolic rate of the skin remained constant during our experiments, the failure of venous congestion to affect the rate of cutaneous respiration indicates that there had been no significant alteration in the rate of exchange of gases between the blood and the skin. When pressure of 40 to $80 \mathrm{~mm}$. of mercury is applied to the upper arm by means of a pneumatic cuff, the flow of blood through the limb is promptly retarded. As a consequence, active compensating dilatation of the minute vessels develops, and the circulation to the extremity returns toward its normal state (5). The 
failure of venous congestion to affect the rate of exchange of carbon dioxide and oxygen between the blood and the skin probably is due to this vasodilatation.

Our results differ from those of Barratt (6) who observed that the application of a ligature to the upper extremity caused a definite increase in the rate of carbon dioxide elimination through the skin of that arm. Barratt employed higher pressures than we did for he stated that, in his subjects, the radial pulsation was barely perceptible after applying the ligature. In our subjects the pressure in the cuff did not exceed diastolic blood pressure and the volume of the pulse was not appreciably altered. Blood flow through the arm, therefore (7), was decreased to a less extent in our experiments than in those of Barratt.

An extreme reduction in blood flow through the arm would be accompanied by an increased carbon dioxide tension of the capillary blood and a diminished oxygen tension. A rise in carbon dioxide tension of the blood results in an increased rate of carbon dioxide elimination through the skin, and a decrease in oxygen tension causes an accelerated rate of oxygen absorption (8). The observation of Barratt (6) that the rate of carbon dioxide elimination through the skin increased after the application of a ligature to the arm therefore indicates that the ligature had produced an extreme reduction of blood flow through the arm.

\section{SUMMARY}

1. The rates of carbon dioxide elimination and oxygen absorption through the skin of the arm were measured before and during the presence of venous congestion produced by applying pressures of 40 to $80 \mathrm{~mm}$. of mercury to the upper arm.

2. Venous congestion did not alter the rate of cutaneous respiratory exchange.

3. The results of the investigation indicate that venous congestion of the degrees employed has no effect on the rate of exchange of carbon dioxide and oxygen between the blood and the skin.

\section{BIBLIOGRAPHY}

1. Shaw, L. A., Messer, A. C., and Weiss, S., Am. J. Physiol., 1929, xc, 107. Cutaneous Respiration in Man. I. Factors Affecting the Rate of Carbon Dioxide Elimination and Oxygen Absorption.

2. Shaw, L. A., and Messer, A. C., Am. J. Physiol., 1930, xcv, 13. Cutaneous Respiration in Man. II. The Effect of Temperature and of Relative Humidity upon the Rate of Carbon Dioxide Elimination and Oxygen Absorption.

3. Ernstene, A. C., and Volk, M. C., J. Clin. Invest., 1932, xi, 383. Cutaneous Respiration in Man. VI. The Effect of Drugs on the Rate of Carbon Dioxide Elimination and Oxygen Absorption. 
4. Ernstene, A. C., and Volk, M. C., J. Clin. Invest., 1932, xi, 363. Cutaneous Respiration in Man. IV. The Rate of Carbon Dioxide Elimination and Oxygen Absorption in Normal Subjects.

5. Lewis, T., The Blood Vessels of the Human Skin and Their Responses. Shaw and Sons, London, 1927.

6. Barratt, W., J. Physiol., 1897, xxi, 192. On the Normal and Pathological Elimination of Carbonic Acid and of Water by the Skin.

7. Stewart, G. N., Arch. Int. Med., 1912, ix, 706. Studies on the Circulation in Man. V. Effect on the Blood Flow in the Hand of Applying Different Pressures to the Upper Arm; A Contribution to the Clinical Measurement of Blood Pressure.

8. Shaw, L. A., and Messer, A. C., Am. J. Physiol., 1931, xcviii, 93. Cutaneous Respiration in Man. III. The Permeability of the Skin to Carbon Dioxide and Oxygen as Affected by Altering their Tension in the Air Surrounding the Skin. 